\title{
Study of Correlation between Fibroscan and Resistin Level in Non-Alcoholic Fatty Liver Disease Patient
}

\author{
Atef Abo El Soud ${ }^{1}$, Ashraf Dawood ${ }^{2}$, Sherien Abd El-Aziz Bayoumi El-Kashash*2, Mohsen El Khayat ${ }^{1}$ \\ Departments of ${ }^{1}$ Tropical Medicine and ${ }^{2}$ Biochemistry, Faculty of Medicine, Menoufia University, Menoufia, Egypt \\ *Corresponding Author: Sherien Abd El-Aziz Bayoumi El-Kashash, Mobile: +201006660886,
}

E-mail: magdy19762006@yahoo.com

\begin{abstract}
Background: Hormone resistin is linked to the development of insulin resistance, but direct evidence of resistin levels in humans with nonalcoholic fatty liver disease (NAFLD) is lacking.

Objective: To study the role of fibroscan and resistin level in diagnosis of nonalcoholic fatty liver patients.

Methods: This study was conducted on 60 NAFLD patients, 27 patients with nonalcoholic steatohepatitis (NASH), and 33 patients with simple steatosis, who were admitted to Tropical Medicine Department in Shebin El-Kom Fever Hospital and 30 healthy subjects as control. Patients were subjected to meticulous history taking, clinical examination, routine laboratory investigations, abdominal ultrasound, fibroscan, and measurement of serum resistin level.

Results: Serum resistin can be used to discriminate between simple steatosis group and NASH group at a cutoff level of $>10.5$, with $53.3 \%$ sensitivity, $83.3 \%$ specificity, $76.1 \%$ PPV and $64.1 \%$ NPV (AUC $=0.73$ and p-value $=0.002$ ). Also, there was a significant difference in fibroscan score in comparison between groups, NASH group represented the highest score. There was a significant relation between serum resistin level and fibroscan score in both NASH and simple steatosis groups.

Conclusion: Fibroscan and serum resistin level can be used for diagnosis of nonalcoholic fatty liver and for discrimination between simple steatosis and NASH patients.
\end{abstract}

Keywords: Fatty Liver, Fibroscan, Non Alcoholic, Resistin.

\section{INTRODUCTION}

Nonalcoholic fatty liver disease (NAFLD) is now considered the most prevalent chronic liver disease (CLD) worldwide. It is expected to become the most common cause of end-stage liver disease (i.e., cirrhosis and hepatocellular carcinoma) in the near future and, consequently, the most common indication for liver transplantation ${ }^{(\mathbf{1})}$. Liver biopsy is the gold standard test for diagnosis, grading, and histological assessment of NAFLD, and a four point histopathologic grading system is used to assess severity of steatosis that ranges from 0 to 3, depending on presence of the percentage of fat-containing hepatocytes ${ }^{(2)}$.

But the value of a liver biopsy for the diagnosis of NAFLD in routine clinical practice is controversial, especially in the presence of a generally good prognosis for most patients with NAFLD, the lack of an established form of effective therapy, and the risks and costs associated with the liver biopsy ${ }^{(3)}$. Liver stiffness (LS) measurement by transient elastography (TE) is a very promising non-invasive method for the diagnosis of fibrosis in chronic liver diseases. A strong correlation between LS measurements and liver fibrosis stages, assessed by simultaneous liver biopsies, have been reported in nonalcoholic steatohepatitis (NASH) ${ }^{(4)}$.

Resistin, also known as adipose tissue-specific secretory factor (ADSF), is a cysteine-rich polypeptide encoded by the RETN gene. It is believed to play a significant role in the development of insulin resistance. In humans, it is proved to be a 108-amino acid polypeptide expressed in adipocytes, pancreatic cells, muscle, and mononuclear cells ${ }^{(5)}$. Increased serum resistin levels are associated with metabolic syndrome and insulin resistance. In patients with NAFLD, serum resistin levels were higher than those in control lean and obese patients ${ }^{(6)}$.

The aim of the present study was to study the role of fibroscan and resistin level in diagnosis of nonalcoholic fatty liver patients.

\section{PATIENTS AND METHODS}

The present study was conducted in Shebin ElKom Fever Hospital, including 90 participants. The studied patients were recruited from Tropical Medicine Department during the period from July 2019 to January 2020. 60 subjects enrolled in this study with NAFLD and 30 non obese apparently healthy people. Diagnosis based on chronic elevation of transaminases (> 1.5 times the upper normal value for 3 months in absence of chronic liver disease) and bright liver by U/S and diagnosis confirmed by liver biopsy. Subjects were classified into three groups:

- Group I: include 27 patients with NASH.

- Group II: include 33 patients with simple steatosis.

- Group III: include 30 healthy subjects as control.

The following patients were excluded:

1- Patients who are known to be alcoholic.

2- Patients who are known to be positive for hepatitis $\mathrm{C}$ or B.

3- Autoimmune hepatitis.

4- Primary biliary cirrhosis.

5- Obstructive liver disease.

6- Alcohol consumption.

This article is an open access article distributed under the terms and conditions of the Creative Commons Attribution (CC BY-SA) license (http://creativecommons.org/licenses/by/4.0/) 
7- History of statin drug intake.

8- Metabolic liver disease.

Patient's inclusion criteria (for group 1 and 2): liver biopsy.

NAFLD patients diagnosed and confirmed by

\section{All patients were subjected to the following:}

Full detailed history taking with stress on past history of weight gain, dyslipidemia, hypertension, obstructive sleep apnea, polycystic ovary syndrome, chronic hepatitis $\mathrm{C}$, diabetes mellitus, family history of metabolic syndrome. Abdominal ultrasonography was done using Chison 6001 Ultrasound for all patients for examination of liver echotecture and size, common bile duct diameter, gall bladder stones, portal vein thrombosis, size of spleen, presence or absence of ascites and presence of any masses. Transient elastography was done for measurement of liver stiffness with FibroScan (Echosens, Paris, France) using $\mathrm{M}$ probe in compliance with the technical recommendations. All participants were evaluated for their height, weight, and body mass index (BMI). Weight was measured to the nearest $0.1 \mathrm{~kg}$ using electronic weight scale with the respondents lightly clothed. Height was measured to the nearest $0.5 \mathrm{~cm}$ with measuring tape while the respondent stood still without shoes. BMI was calculated by the formula, BMI = weight $(\mathrm{kg}) /$ height $\left(\mathrm{m}^{2}\right)$. According to the BMI cutoffs points; underweight (BMI <18.5), normal (18.5-24.9), overweight (25-29.9), and obese class (BMI $\geq 30)$.

Then $10 \mathrm{ml}$ of venous blood were withdrawn from every subject then; $8 \mathrm{ml}$ were transferred into a plain tube, centrifuged for $10 \mathrm{~min}$ at $4000 \mathrm{rpm}$. The serum obtained was kept frozen at $-20^{\circ} \mathrm{C}$ till analysis of (liver function tests, Kidney function tests, lipid profile tests and serum resistin level). The remaining $2 \mathrm{ml}$ were transferred into EDTA tube for complete blood count (CBC). Human serum resistin was assayed using SUN
RED (ST) ELISA Kit, from Shanghai (Catalogue no. 201-12-0339).

\section{Test principle:}

The kit uses a double-antibody sandwich enzyme-linked immunosorbent assay. The chroma of color and the concentration of the human substance resistin of sample were positively correlated.

Assay procedure: The instructions of the producer of the kit were followed.

Ethical approval and written informed consent: An approval of the study was obtained from Menoufia University Academic and Ethical Committee. Every patient signed an informed written consent for acceptance of the operation.

\section{Statistical Analysis}

The collected data were coded, processed and analyzed using the SPSS (Statistical Package for the Social Sciences) version 22 for Windows ${ }^{\circledR}$ (IBM SPSS Inc, Chicago, IL, USA). Data were tested for normal distribution using the Shapiro Wilk test. Qualitative data were represented as frequencies and relative percentages. Quantitative data were expressed as mean \pm SD (Standard deviation) and were compared by oneway ANOVA test and Tukey's post hoc test. ROC curve: was done to detect a cutoff of serum resistin and fibroscan score. $\mathrm{P}$ value $<0.05$ was considered significant.

\section{RESULTS}

Statistical analysis revealed that there was a significant difference in the mean of ALT in all groups and a significant difference in the mean of AST and GGT between NASH and control group and between simple steatosis and control group. But no significance in comparing between NASH and simple steatosis group (Table 1).

Table (1): Comparison between groups according to biochemical finding

\begin{tabular}{|c|c|c|c|c|c|c|c|}
\hline & \multicolumn{3}{|c|}{ Groups } & \multirow[b]{3}{*}{ P-value } & & & \\
\hline & \multirow{2}{*}{$\begin{array}{c}\text { Group I N=27 } \\
\text { Mean } \pm \text { S.D. }\end{array}$} & \multirow{2}{*}{$\begin{array}{c}\text { Group II N=33 } \\
\text { Mean } \pm \text { S.D. }\end{array}$} & Group III N=30 & & \multicolumn{3}{|c|}{ TUKEY'S } \\
\hline & & & Mean \pm S.D & & $\begin{array}{l}\text { Group I } \\
\text { and II }\end{array}$ & $\begin{array}{l}\text { Group I } \\
\text { and III }\end{array}$ & $\begin{array}{c}\text { Group } \\
\text { II and } \\
\text { III }\end{array}$ \\
\hline ALT (U/L) & $73.33 \pm 11.02$ & $62.07 \pm 6.58$ & $28.80 \pm 9.42$ & $<0.001 *$ & $<0.001 *$ & $<0.001 *$ & $<0.001 *$ \\
\hline $\operatorname{AST}(\mathbf{U} / \mathbf{L})$ & $36.20 \pm 6.01$ & $40.37 \pm 6.21$ & $26.53 \pm 8.76$ & $<0.001 *$ & 0.065 & $<0.001 *$ & $<0.001 *$ \\
\hline GGT (U/L) & $78.47 \pm 10.27$ & $71.23 \pm 8.01$ & $32.00 \pm 7.96$ & $<0.001 *$ & 0.006 & $<0.001 *$ & $<0.001 *$ \\
\hline Bill & $0.89 \pm 0.97$ & $0.56 \pm 0.21$ & $0.87 \pm 0.27$ & 0.066 & NA & NA & NA \\
\hline Alb (g/dL) & $3.47 \pm 0.48$ & $3.69 \pm 0.28$ & $3.82 \pm 0.36$ & 0.003* & 0.065 & 0.002 & 0.424 \\
\hline Creat (mg) & $0.96 \pm 0.26$ & $0.93 \pm 0.25$ & $0.79 \pm 0.26$ & 0.033 & 0.917 & 0.039 & 0.099 \\
\hline INR & $1.22 \pm 0.20$ & $1.12 \pm 0.12$ & $1.10 \pm 0.10$ & $0.005 *$ & 0.043 & 0.006 & 0.757 \\
\hline
\end{tabular}

NA=Not applicable

There was a statistical significant relation between groups according to TGs, cholesterol, HDL and

LDL. NASH group had the highest mean value in TG, Chol. and LDL (Table 2). 
Table (2): Comparison between groups according to lipid profile

\begin{tabular}{|c|c|c|c|c|c|c|c|}
\hline & \multicolumn{6}{|c|}{ Groups } & \multirow{3}{*}{ P-value } \\
\hline & \multicolumn{2}{|c|}{ Group I } & \multicolumn{2}{|c|}{ Group II } & \multicolumn{2}{|c|}{ Group III } & \\
\hline & \multicolumn{2}{|c|}{ Mean \pm S.D. } & \multicolumn{2}{|c|}{ Mean \pm S.D. } & \multicolumn{2}{|c|}{ Mean \pm S.D } & \\
\hline $\mathrm{TG}_{\mathrm{s}}(\mathrm{ng} / \mathrm{mL})$ & 194.23 & \pm 31.20 & 181.27 & \pm 28.95 & 102.53 & \pm 16.25 & $<0.001 *$ \\
\hline Chol. (mg/dL) & 208.53 & \pm 31.12 & 201.43 & \pm 21.85 & 183.17 & \pm 19.79 & $<0.001 *$ \\
\hline HDL (mg/dL) & 45.13 & \pm 8.08 & 44.40 & \pm 7.52 & 56.33 & \pm 6.74 & $<0.001 *$ \\
\hline LDL (mg/dL) & 126.40 & \pm 28.84 & 123.27 & \pm 21.94 & 106.43 & \pm 18.04 & 0.003* \\
\hline
\end{tabular}

There was a significant difference in fasting blood glucose, HbA1c, F. insulin and HOMA-IR in comparing between groups. NASH group had the highest mean value in all parameters (Table 3).

Table (3): Comparison between groups according to glucose metabolism

\begin{tabular}{|c|c|c|c|c|}
\hline & \multicolumn{3}{|l|}{ Groups } & \multirow{3}{*}{ P-value } \\
\hline & \multirow{2}{*}{$\begin{array}{l}\text { Group I } \\
\text { Mean } \pm \text { S.D. }\end{array}$} & \multirow{2}{*}{$\begin{array}{l}\text { Group II } \\
\text { Mean } \pm \text { S.D. }\end{array}$} & \multirow{2}{*}{$\begin{array}{l}\text { Group III } \\
\text { Mean } \pm \text { S.D }\end{array}$} & \\
\hline & & & & \\
\hline FBS (mg/dL) & $165.57 \pm 2.14$ & \pm 28.79 & $83.90 \pm 9.47$ & $<0.001 *$ \\
\hline HbA1c & $12.53 \pm 2.52$ & \pm 1.92 & $5.59 \pm 0.74$ & $<0.001 *$ \\
\hline F. Insulin (mcU/mL) & \pm 2.9 & \pm 2.9 & \pm 2.03 & $<0.001 *$ \\
\hline HOMA-IR (mg/kg/min) & \pm 0.6 & \pm 0.5 & \pm 0.05 & $<0.001 *$ \\
\hline
\end{tabular}

There was a significant difference in fibroscan score in comparison between groups. NASH group had the highest score with $\mathrm{p}$ value $<0.001$ (Table 4).

Table (4): Comparison between groups according to fibroscan score

\begin{tabular}{|c|c|c|c|c|c|c|c|}
\hline & \multicolumn{3}{|l|}{ Groups } & & & & \\
\hline & Group I & Group II & Group III & \multicolumn{3}{|c|}{ Tukey's } & P-value \\
\hline & Mean \pm S.D. & Mean \pm S.D. & Mean \pm S.D & I and II & I and III & II and III & \multirow[b]{2}{*}{$<0.001^{\prime}$} \\
\hline $\begin{array}{l}\text { Fibroscan } \\
(\mathrm{dB} / \mathrm{m})\end{array}$ & $11 \pm 3$ & $7 \pm 1$ & $4 \pm 1$ & $<0.001 *$ & $<0.001 *$ & $<0.001 *$ & \\
\hline
\end{tabular}

There was a significant difference in resistin level in comparison between groups with $\mathrm{P}$ value $<0.001$ (Table 5).

Table (5): Comparison between groups according to resistin level

\begin{tabular}{|c|c|c|c|c|c|c|c|}
\hline & \multicolumn{9}{|c|}{ Groups } & \multicolumn{4}{|c|}{ LSD } & P-value \\
\cline { 2 - 8 } & Group I & Group II & Group III & \multicolumn{3}{|c|}{ I } \\
\cline { 2 - 8 } & Mean \pm S.D. & Mean \pm S.D. & Mean \pm S.D & I and II & $\begin{array}{c}\text { I and } \\
\text { III }\end{array}$ & $\begin{array}{c}\text { II and } \\
\text { III }\end{array}$ & \multirow{20.001*}{*}{} \\
\hline Resistin & $10.1 \pm 2.4$ & $7.8 \pm 1.1$ & $5.2 \pm 1.8$ & $<\mathbf{0 . 0 0 1} *$ & $<\mathbf{0 . 0 0 1} *$ & $\mathbf{0 . 0 0 1}$ & \\
\hline
\end{tabular}

There was a significant positive correlation between serum resistin level and fibroscan score in both NASH and simple steatosis groups (Figures 1 and 2). 


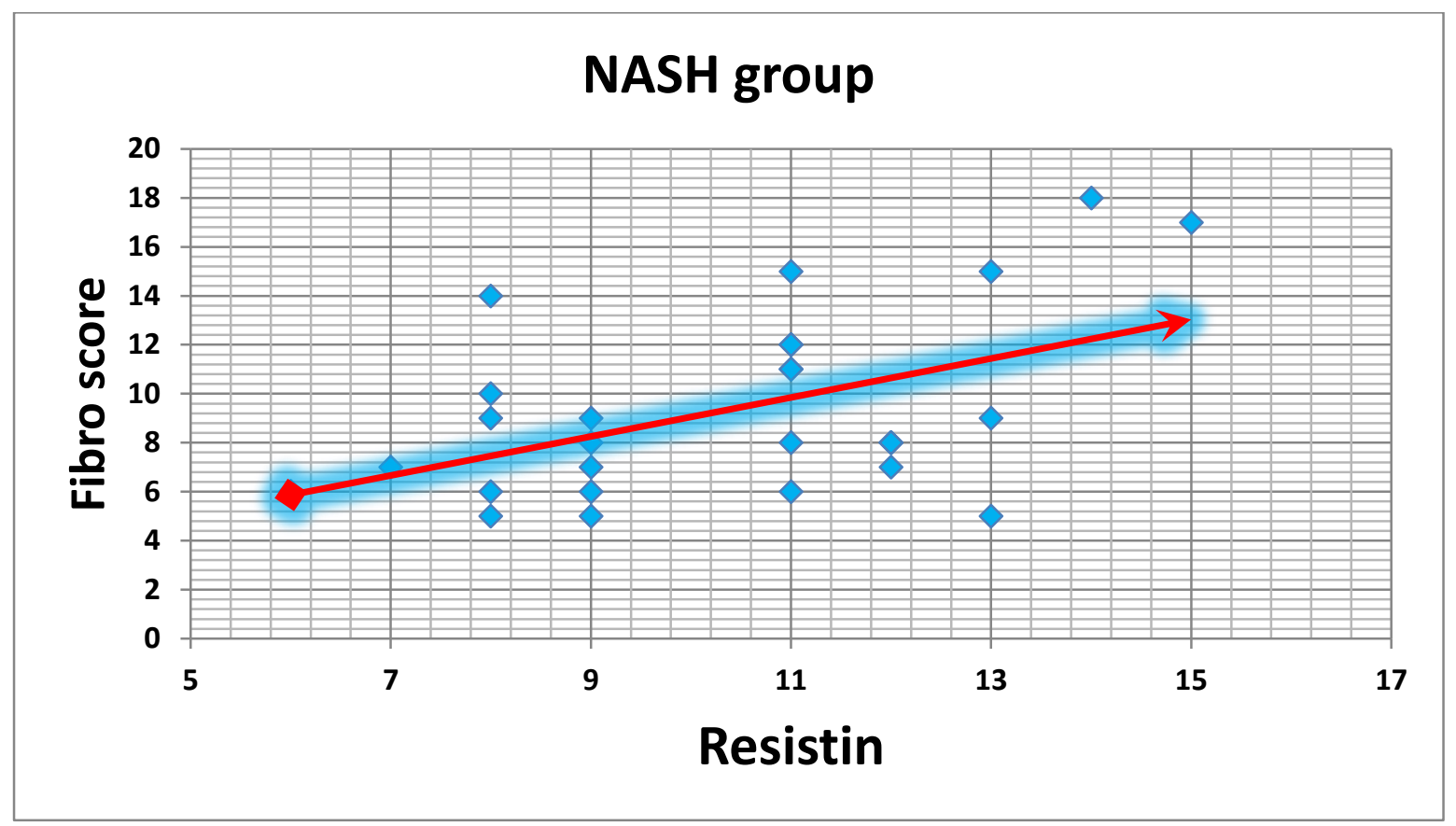

Fig. (1): Positive correlation between serum resistin and fibroscan score in NASH group

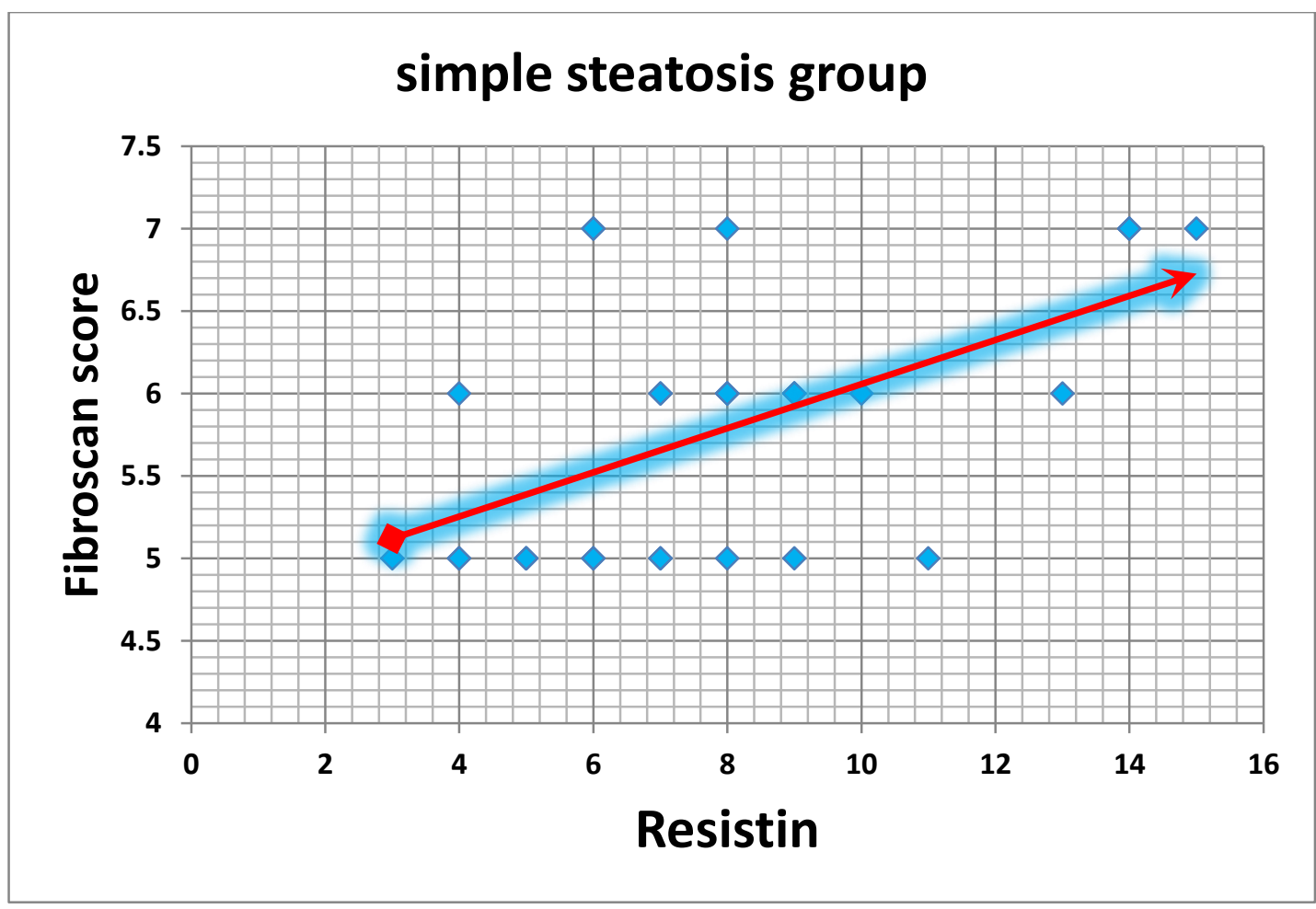

Fig. (2): Positive correlation between serum resistin and fibroscan score in simple steatosis group

Using ROC curve, it was shown that serum resistin can be used to discriminate between simple steatosis group and NASH group at a cutoff level of $>10.5$, with $53.3 \%$ sensitivity, $83.3 \%$ specificity, $76.1 \%$ PPV and $64.1 \%$ NPV $($ AUC $=0.73$ and $\mathrm{p}$-value $=0.002)($ Figure 3$)$. 


\section{Simple steatosis \& NASH groups}

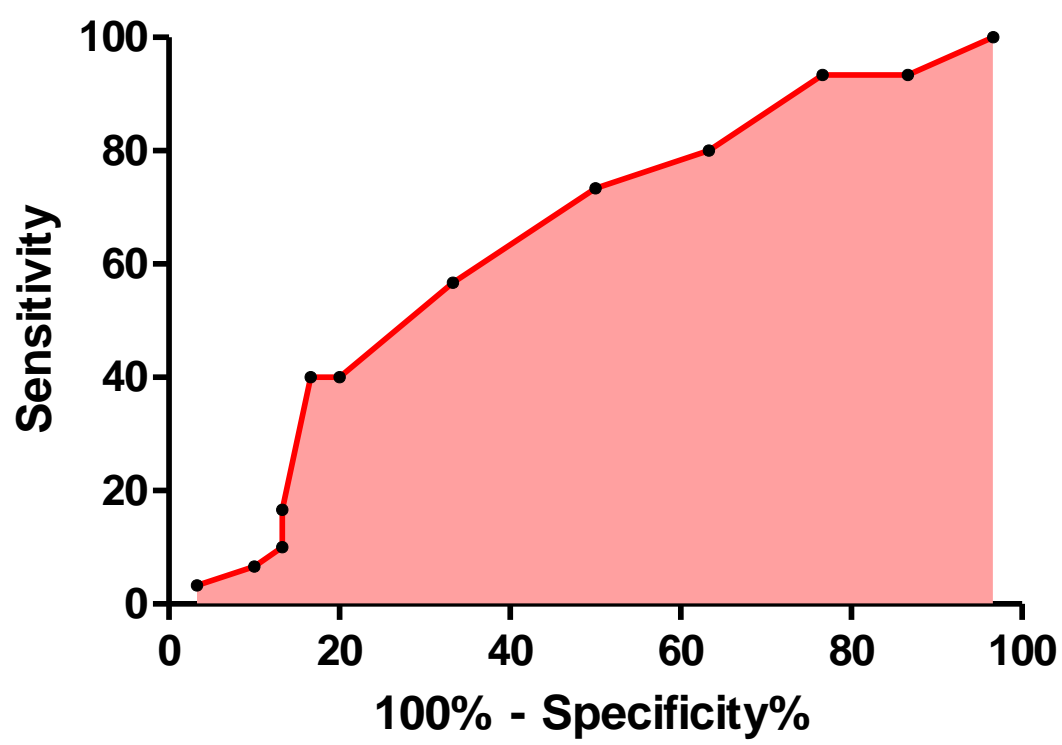

Fig. (3): ROC curve between NASH group and simple steatosis group as regard serum resistin.

Using ROC curve, it was shown that fibroscan score can be used to discriminate between simple steatosis group and NASH group at a cutoff level of $>7.5$, with $60 \%$ sensitivity, $100 \%$ specificity, $100 \%$ PPV and $71.4 \%$ NPV $($ AUC $=0.83$ and p-value $<0.001)($ Figure 4$)$.

\section{Fibroscan score}

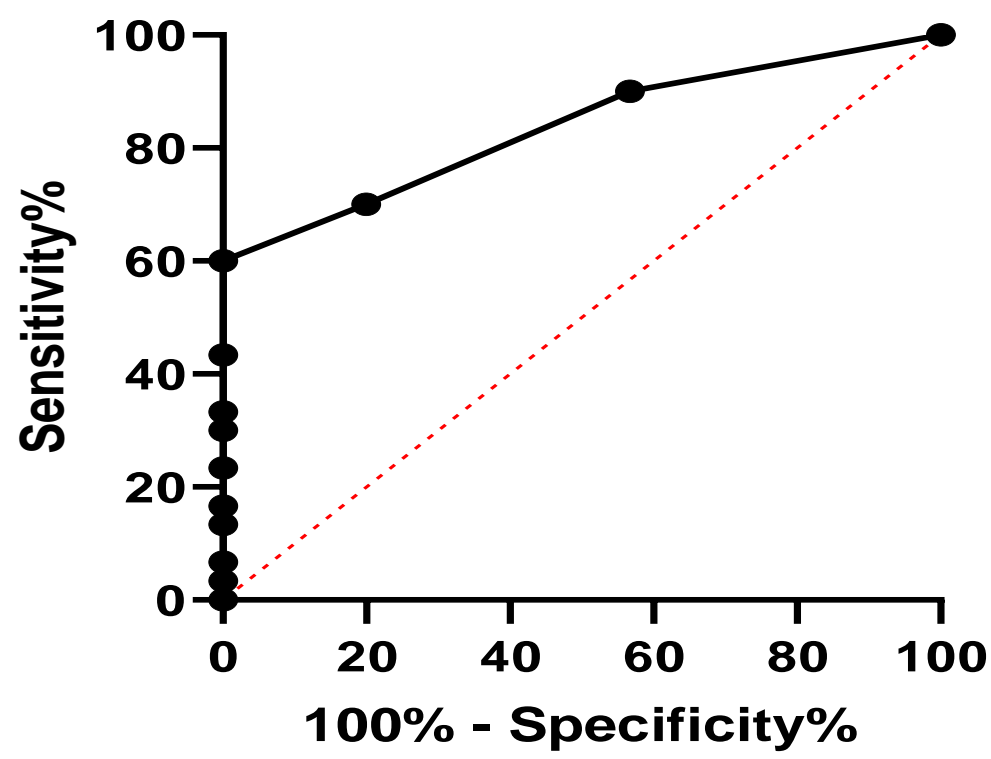

Fig. (4): ROC curve between NASH group and simple steatosis group as regard fibroscan score.

\section{DISCUSSION}

The present study reported that there were statistically significant differences in cholesterol mean values among the 3 groups. These results were in agreement with the studies of Yang $\boldsymbol{e t}$ al. ${ }^{(7)}$ providing that cholesterol levels are increased with NAFLD and NASH more than in normal subjects. But these results were in disagreement with Murad et al. (8) who reported that there was no significant difference in serum total cholesterol or triglyceride levels in patients when compared with the controls with $p$ value 0.446 and 0.075 respectively. Also the results of Albracht-Schulte et al. ${ }^{(9)}$ study disagreed with the present study. The results reported that TG levels were not elevated.

FBG and $\mathrm{HbAlc}$ mean values showed statistically significant differences in between the 3 groups. These results agreed with study of Nazal $\boldsymbol{e t} \boldsymbol{a l}$. ${ }^{(10)}$ who reported that there was a significant difference 
between groups in the mean of fasting glucose level with $p$ value 0.01 .

In the present study fasting insulin and HOMA-IR mean values showed statistically significant differences among the 3 groups. These results agreed with study of Sanal and Sarin ${ }^{(11)}$.

A significant difference was found regarding mean \pm SD of BMI between the studied groups. This comes in accordance with the results of Nazal $\boldsymbol{e t} \boldsymbol{a l}$. ${ }^{(10)}$ who reported that there was a significant difference between groups as regards BMI with p value 0.01 .

In the present study the mean values of fibroscan score showed statistically significant differences among the studied groups. This agreed with the results of the study performed by Pathik $\boldsymbol{e} t$ al. ${ }^{(12)}$. As regards serum resistin level the current study found that there were statistically significant differences between the studied groups. These results were in agreement with Shen et al. ${ }^{(13)}$ and Abdel Monem et al. ${ }^{(14)}$.

The present result reported that the serum levels of resistin were significantly higher in patients with NASH compared to patients with simple steatosis. Mohamed et al. ${ }^{(15)}$ also found a significant difference between the NAFLD group $(16.2 \pm 4)$ and control group $(3.4 \pm 1.1)$, but they reported no significant difference in NAFLD subtypes where NASH patients $(19.2 \pm 3.6)$ had higher resistin than non-NASH patients $(13.5 \pm 2.7 \mathrm{ng} / \mathrm{ml})$ with a significant difference between them. On the contrary, these results disagreed with Wong et al. ${ }^{(16)}$.

In the present study serum resistin level was used to discriminate between simple steatosis group and control group at a cutoff level of $>6.5$. Abdel Monem et al. ${ }^{(14)}$ study reported that resistin level was at cut off value $>3.7 \mathrm{ng} / \mathrm{ml}$ with $95 \% \mathrm{SN}, 89.4 \% \mathrm{SP}$, 90\% PPV and $100 \%$ NPV. On the other hand serum resistin level accuracy discrimination of NASH group from simple steatosis group was at cut off value $>10.5$ $\mathrm{ng} / \mathrm{ml}$.

\section{CONCLUSIONS}

Serum resistin level and fibroscan can be used to diagnose NAFLD patients and can be used to discriminate NASH patients from simple steatosis patients.

\section{REFERENCES}

1. Grgurevic I, Podrug K, Mikolasevic I et al. (2020): Natural history of nonalcoholic fatty liver disease: Implications for clinical practice and an individualized approach. Canadian Journal of Gastroenterology and Hepatology. https://doi.org/10.1155/2020/9181368.

2. Brunt $\mathbf{E}$ (2018): Assessment of liver histology. In: Zakim and Boyer's Hepatology. A Textbook of Liver Disease; https://www.elsevier.com/books/zakim-andboyers-hepatology/9780323375917
3. Paul J (2020): Recent advances in non-invasive diagnosis and medical management of non-alcoholic fatty liver disease in adult. Egyptian Liver Journal, 10: 37. https://doi.org/10.1186/s43066-020-00043-x.

4. Sharma P, Agarwal R, Dhawan S et al. (2017): Transient elastography (Fibroscan) in patients with noncirrhotic portal fibrosis. J Clin Exp Hepatol., 7(3):230234.

5. Su K, Li Y, Zhang D et al. (2019): Relation of circulating resistin to insulin resistance in type 2 diabetes and obesity: A systematic review and meta-analysis. Front. Physiol., 10: 1399-1409.

6. Hegazy M, Abo-Elfadl S, Mostafa A et al. (2014): Serum resistin level and its receptor gene expression in liver biopsy as predictors for the severity of nonalcoholic fatty liver disease. Euroasian Journal of HepatoGastroenterology, 4(2)59-62.

7. Yang S, Kwak S, Lee J et al., (2019): Nonalcoholic fatty liver disease is an early predictor of metabolic diseases in a metabolically healthy population. PLoS ONE,14(11): 0224626.

8. Murad A, Hassan H, Husein H et al. (2010): Serum resistin levels in nonalcoholic fatty liver disease and their relationship to severity of liver disease. JEMDSA., 15(1):53-56.

9. Albracht-Schulte K, Rosairo S, Ramalingam L et al. (2019): Obesity, adipocyte hypertrophy, fasting glucose, and resistin are potential contributors to nonalcoholic fatty liver disease in South Asian women. Diabetes, Metabolic Syndrome and Obesity. Targets and Therapy, 12: 863-872.

10. Nazal L, Riquelme A, Solís $\mathrm{N}$ et al. (2010): Hypoadiponectinemia and its association with liver fibrosis in morbidly obese patients. Obes Surg., 20: 1400-1407.

11.Sanal M, Sarin S (2009): Serum adipokine profile in Indian men with nonalcoholic steatohepatitis: Serum adiponectin is paradoxically decreased in lean vs. obese patients. Diabetes \& Metabolic Syndrome: Clinical Research \& Reviews, 3(4)198-203.

12.Pathik P, Dattatray S, Ajay C et al. (2015): Comparison of fibroscan to simple noninvasive screening tools in predicting fibrosis in NAFLD patients of Western India with high risk of liver fibrosis. Ann Gastroenterol., 28(2):281-286.

13. Shen C, Zhao C, Wang $W$ et al. (2014): The relationship between hepatic resistin overexpression and inflammation in patients with nonalcoholic steatohepatitis. BMC Gastroenterology, 14(1): 39-46.

14. Abdel Monem S, Fathy T, Shalaby S et al. (2018): Serum resistin level as a diagnostic marker in nonalcoholic steatohepatitis. Afro-Egypt $\mathrm{J}$ Infect Endem Dis., 8(3)140-148.

15. Mohamed A, Shousha W, Shaker O et al. (2014): Role of serum adiponectin, il-6 and hs crp in nonalcoholic fatty liver Egyptian patients. International Journal of Biochemistry Research \& Review, 4(6)493-504.

16. Wong V, Hui A, Tsang $S$ et al. (2006): Metabolic and adipokine profile of Chinese patients with nonalcoholic fatty liver disease. Clin Gastroenterol Hepatol., 4:115461. 